\title{
A determinação da profundidade do nível d'água pelo método da refração sísmica
}

Otávio Coaracy Brasil Gandolfo - gandolfo@ipt.br Instituto de Pesquisas Tecnológicas de São Paulo - IPT

\section{Copyright 2014, SBGf - Sociedade Brasileira de Geofísica}

Este texto foi preparado para a apresentação no VI Simpósio Brasileiro de Geofísica, Porto Alegre, 14 a 16 de outubro de 2014. Seu conteúdo foi revisado pelo Comitê Técnico do VI SimBGf, mas não necessariamente representa a opinião da SBGf ou de seus associados. É proibida a reprodução total ou parcial deste material para propósitos comerciais sem prévia autorização da SBGf.

\section{Abstract}

This paper presents the results of a refraction seismic survey, using compressional waves $(P)$ and shear waves (S), to estimate the depth to the water table in an unconfined aquifer. The use of both $P$ and S-waves can diminish some ambiguities. Seismic refraction data were processed with conventional "delay-times" method and with tomographic inversion and the final models were compared. The water table depth was well determined by the P-wave section (obtained by "delay times" method) and the combined $P$ and S-wave data processed with tomographic inversion, using Poisson's ratio values.

\section{Introdução}

Diversos métodos geofísicos são comumente empregados para a determinação da profundidade do nível d'água em um aquífero livre, destacando-se a eletrorresistividade, os métodos eletromagnéticos e o GPR. Dependendo de certas condições existentes "in situ", o método da refração sísmica, gerando e registrando a onda compressional (onda $\mathrm{P}$ ), pode também ser utilizado para esta finalidade e apresentar resultados satisfatórios.

Entretanto, poderá surgir uma ambiguidade na interpretação dos resultados, pois o aumento da velocidade da onda sísmica compressional pode ocorrer tanto devido à saturação do terreno como também em decorrência de uma mudança litológica.

Alguns autores sugerem que a utilização adicional da onda de cisalhamento (onda $S$ ) pode contribuir para a solução desta ambiguidade (Dobecki, 1988). A razão é simples. A velocidade da onda $S\left(V_{S}\right)$ não será afetada pela camada saturada abaixo do nível d'água, enquanto a velocidade da onda $P\left(V_{P}\right)$ será fortemente influenciada. Porém, se alguma mudança de litologia ocorrer, é bastante provável que esta modificação afete igualmente $V_{\mathrm{p}}$ e $\mathrm{V}_{\mathrm{s}}$. Portanto, a razão $\mathrm{V}_{\mathrm{p}} / \mathrm{V}_{\mathrm{S}}$ pode ser um parâmetro diagnóstico para distinguir estas duas situações.

\section{Metodologia}

O levantamento da refração sísmica, com o emprego das ondas $\mathrm{P}$ e S, foi realizado em uma linha de 46 metros de extensão, com 24 geofones espaçados de 2 metros.

Para a geração da onda $P$ foi utilizada uma marreta de 5 $\mathrm{kg}$ batendo contra uma placa metálica posicionada sobre o solo e geofones de componente vertical (frequência natural igual a $4,5 \mathrm{~Hz}$ ).

Para a geração da onda $S$ foi utilizado um dormente de madeira posicionado sobre o solo e a marreta batendo contra as suas duas faces opostas laterais, procedimento comumente utilizado para a geração de ondas cisalhantes de polaridades invertidas. Foram realizados 5 pontos de tiro na linha sísmica (Foto 1).

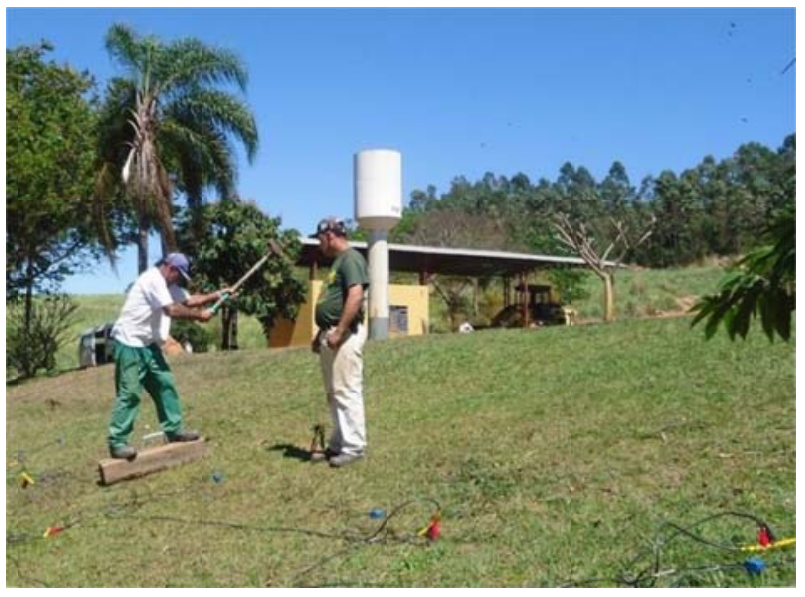

Foto 1 - Levantamento sísmico de refração gerando e registrando a onda S.

Os geofones utilizados foram os de componente horizontal e frequência natural igual a $28 \mathrm{~Hz}$. Os dados foram registrados em um sismógrafo de 24 canais, modelo Geode, fabricado pela Geometrics,

O trabalho foi realizado no município de Itapira-SP. Na área de estudo ocorrem solos residuais formados do intemperismo de gnaisses e migmatitos, constituídos por siltes arenosos com coloração variegada e aumento da fração silte em profundidade, de acordo com informações de sondagens realizadas no local (IPT, 2014).

$\mathrm{Na}$ época da realização do levantamento de campo, o nível d'água encontrava-se a 4 metros de profundidade, informação que foi obtida em um poço de monitoramento existente a poucos metros da linha sísmica. 


\section{Resultados}

No processamento dos dados foi utilizado o software SeisImager, que utiliza no seu processamento três técnicas de inversões: duas delas baseadas no conceito dos "delay times" e outra, na tomografia.

A Figura 1 apresenta o resultado do processamento dos dados de refração utilizando a onda $P$, obtido por uma das técnicas que utiliza os "delay times". A seção processada resultou em um modelo de 3 camadas.

O estrato sísmico inferior que apresenta velocidade de propagação das ondas $P$ igual a $1500 \mathrm{~m} / \mathrm{s}$ corresponde à zona saturada. As duas camadas superiores, com valores de velocidades iguais a $180 \mathrm{~m} / \mathrm{s}$ e $400 \mathrm{~m} / \mathrm{s}$, correspondem à zona não saturada do terreno.

Supondo-se um desconhecimento da profundidade do nível d'água (4 metros) e dos dados de sondagens (que descrevem a presença de material granular e mesma litologia em todo o perfil, com valores do índice NSPT baixos e sem variação expressiva), a terceira camada poderia ser interpretada de forma errônea. A camada subjacente, com $V_{P}$ igual a $1500 \mathrm{~m} / \mathrm{s}$, poderia não ser interpretada como a zona saturada e sim como uma mudança litológica ou alguma alteração em profundidade das propriedades elásticas do mesmo material sobrejacente.

Para eliminar esta ambiguidade, que poderia ocorrer sem o conhecimento das informações obtidas por meio das investigações diretas (poço e sondagens), foram analisados de forma conjunta os dados de refração obtidos com o emprego das ondas $\mathrm{P}$ e das ondas S.

Para esta análise, o processamento dos dados foi efetuado pelo método da inversão por tomografia. Nesta técnica de inversão, o modelo inicial consiste em numerosas camadas, pouco espessas e com um gradiente contínuo de velocidades.

A Figura 2 apresenta a seção modelada resultante da inversão por tomografia das ondas P. O modelo com a distribuição das velocidades mostra valores da ordem de $400 \mathrm{~m} / \mathrm{s}$ próximo à superfície, aumentando gradativamente até alcançar valores em torno de $1600 \mathrm{~m} / \mathrm{s}$ em profundidade.

Considerando-se que a camada saturada esteja na profundidade onde $V_{P}$ seja igual a $1500 \mathrm{~m} / \mathrm{s}$, tal como a seção sísmica obtida pelo método dos "delay times" (Figura 1), observa-se que neste modelo obtido por tomografia as profundidades estão superestimadas. O resultado obtido por este método de processamento não ofereceu resultado satisfatório quanto à determinação correta das profundidades em comparação ao método tradicional com base nos "delay times".

Marques (2008), em um levantamento onde foi utilizada a refração sísmica com onda $P$, apresentou uma seção modelada por inversão tomográfica na qual a posição interpretada do topo rochoso se encontrava a maiores profundidades do que a sua correta posição definida por sondagens mecânicas, mostrando que esta técnica não se aplica em situações onde há uma variação abrupta das velocidades das ondas sísmicas.
Na Figura 3 encontra-se a seção modelada das ondas S, na qual pode ser observado o aumento de $V_{S}$ com a profundidade sem, contudo, apresentar uma elevação muito acentuada a partir de 4 metros.

Uma forma de avaliar o comportamento da razão $V_{\mathrm{P}} / V_{\mathrm{S}}$ é por meio do coeficiente de Poisson dinâmico $(u)$, dada pela seguinte expressão:

$$
v=\frac{\left(\frac{v_{P}}{v_{S}}\right)^{2}-2}{2\left(\frac{v_{P}}{v_{S}}\right)^{2}-2}
$$

Definindo-se um mesmo formato de grid no processamento dos dados, que apresentam em seus nós os valores de $V_{P}$ e de $V_{S}$ calculados pela inversão dos dados (Figura 4), foi possível a determinação dos valores de Poisson em todos os pontos do grid utilizando a equação 1. Dos 576 pontos da malha, foram eliminados apenas 15 por apresentarem valores negativos do parâmetro.

A Figura 5 apresenta a seção obtida com o resultado dos coeficientes de Poisson calculados. Valores superiores a 0,45 (quando a razão $V_{P} / V_{S}$ supera 3,4 ) indicam a saturação do terreno. A posição do nível d'água encontra-se também assinalada na seção.

\section{Conclusões}

Este trabalhou procurou mostrar a importância de se utilizar a onda $\mathrm{S}$ em levantamentos de refração sísmica, juntamente com o usual emprego da onda $P$, para diminuição de ambiguidades na interpretação dos resultados, especificamente quando o objetivo for a determinação da profundidade do nível d'água.

Precauções devem ser tomadas na interpretação das profundidades das camadas quando o processamento for efetuado por técnicas que utilizam a inversão por tomografia.

\section{Referências}

Dobecki, T. L, 1988. Seismic shear waves for lithology and saturation. In: Proceedings of the Second National Outdoor Action Conference on Aquifer Restoration, Ground Water Monitoring and Geophysical Methods. v.II. National Water Well Association, Dublin, Ohio, p.677-695.

IPT, 2014. Elaboração de plano de encerramento do aterro sanitário de Itapira e estudos de viabilidade ambiental em área contígua. (Relatório Técnico № 137.171-205). 91p.

Marques, F. C. 2008. Estudo comparativo entre métodos de interpretação de sísmica de refração rasa a partir de dados de projeto de aproveitamento hidrelétrico no Rio Madeira. Monografia de Trabalho de Graduação. Instituto de Astronomia, Geofísica e Ciências Atmosféricas-USP, $31 p$. 


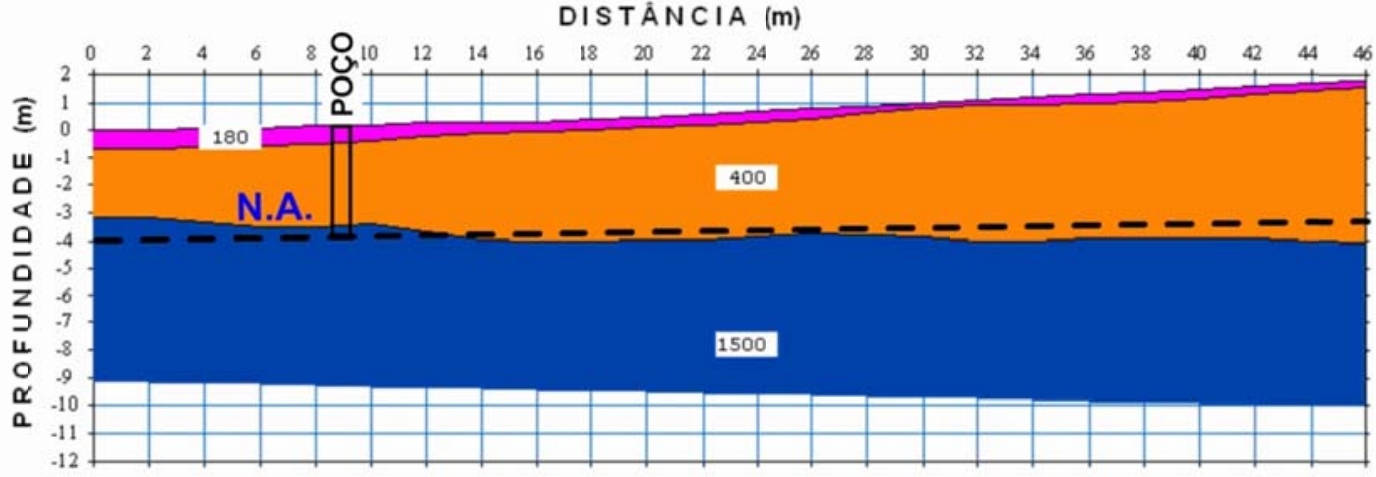

Figura 1 - Seção sísmica modelada (onda P) obtida por processamento que utiliza o método dos "delay times".

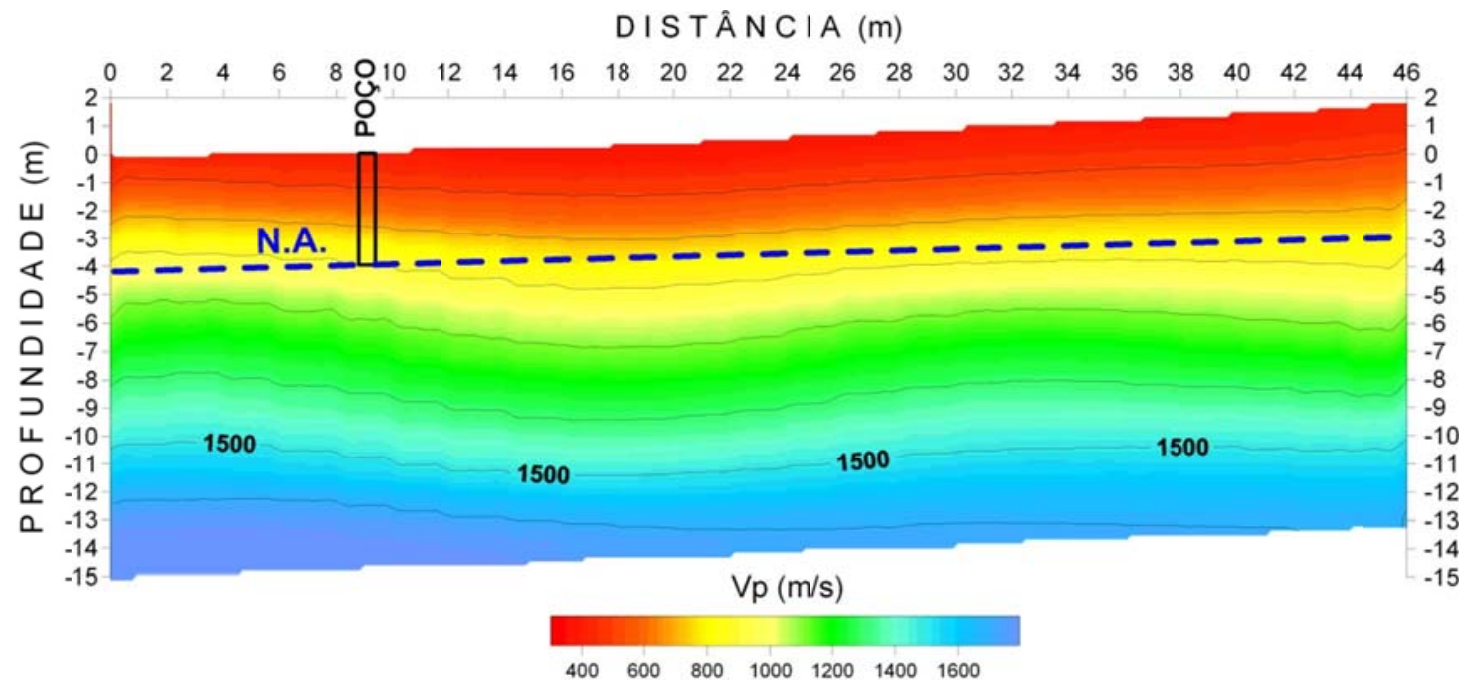

Figura 2 - Seção modelada obtida por inversão tomográfica das ondas P.

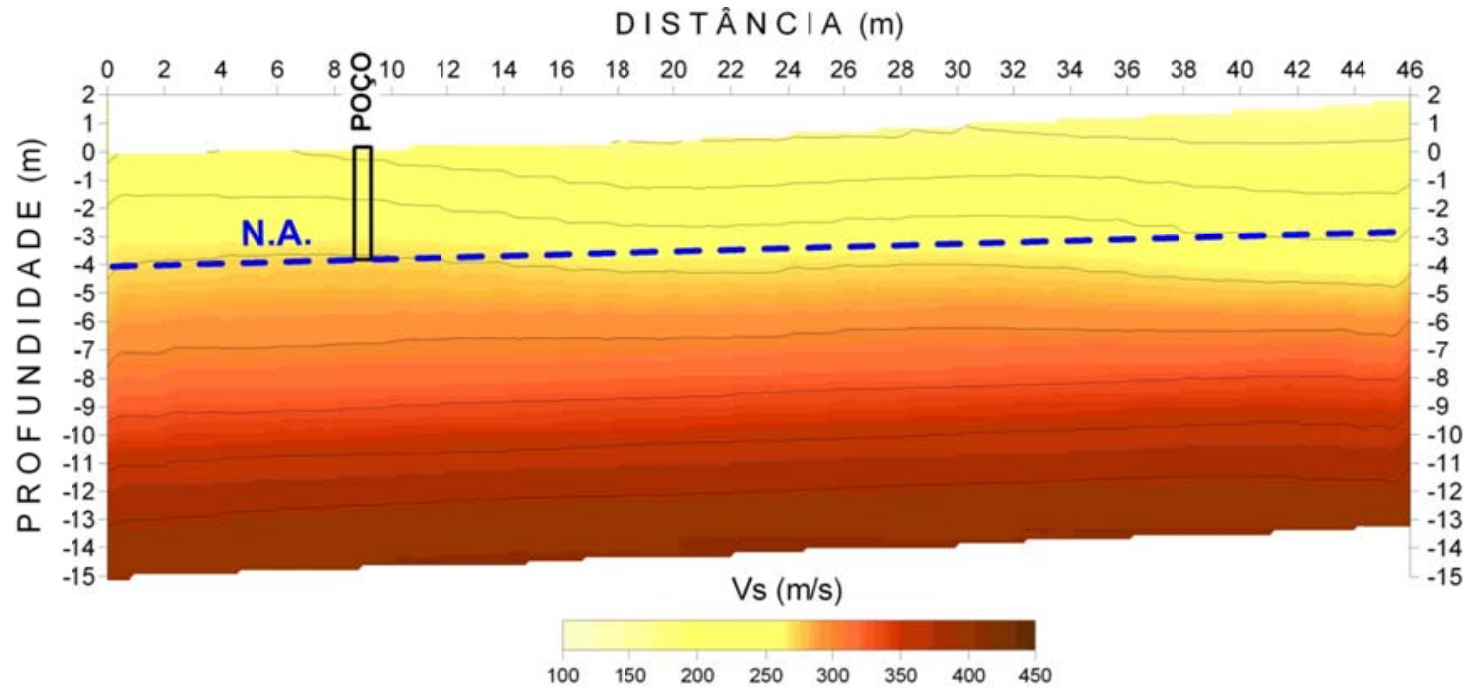

Figura 3 - Seção modelada obtida por inversão tomográfica das ondas S. 


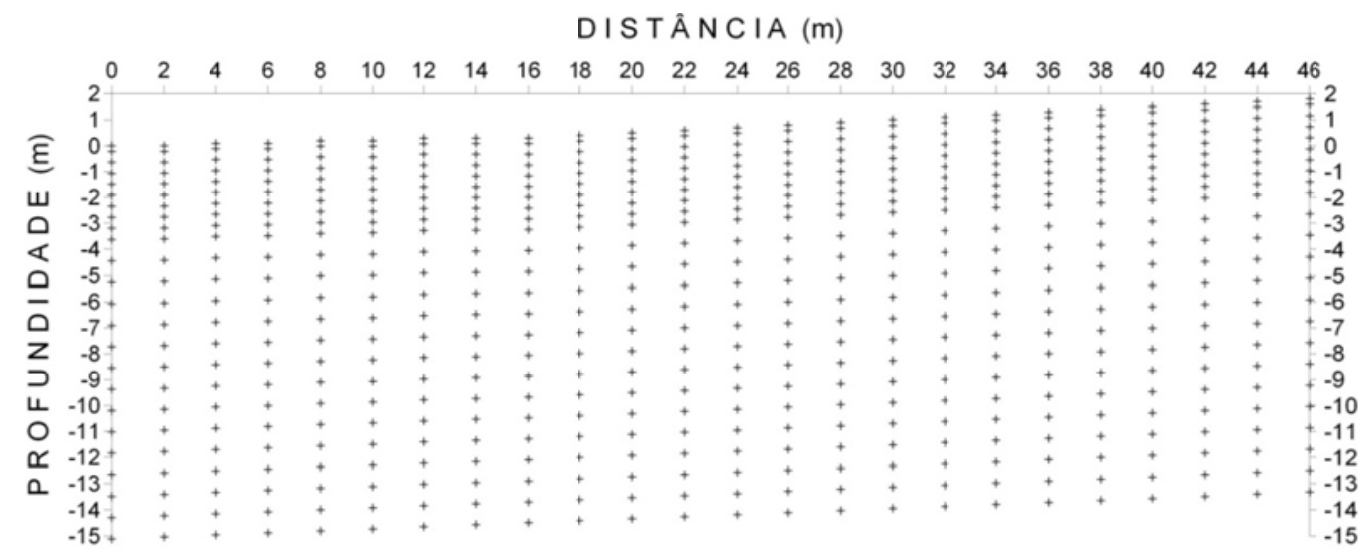

Figura 4 - Malha de pontos utilizada para a determinação dos valores do coeficiente de Poisson dinâmico.

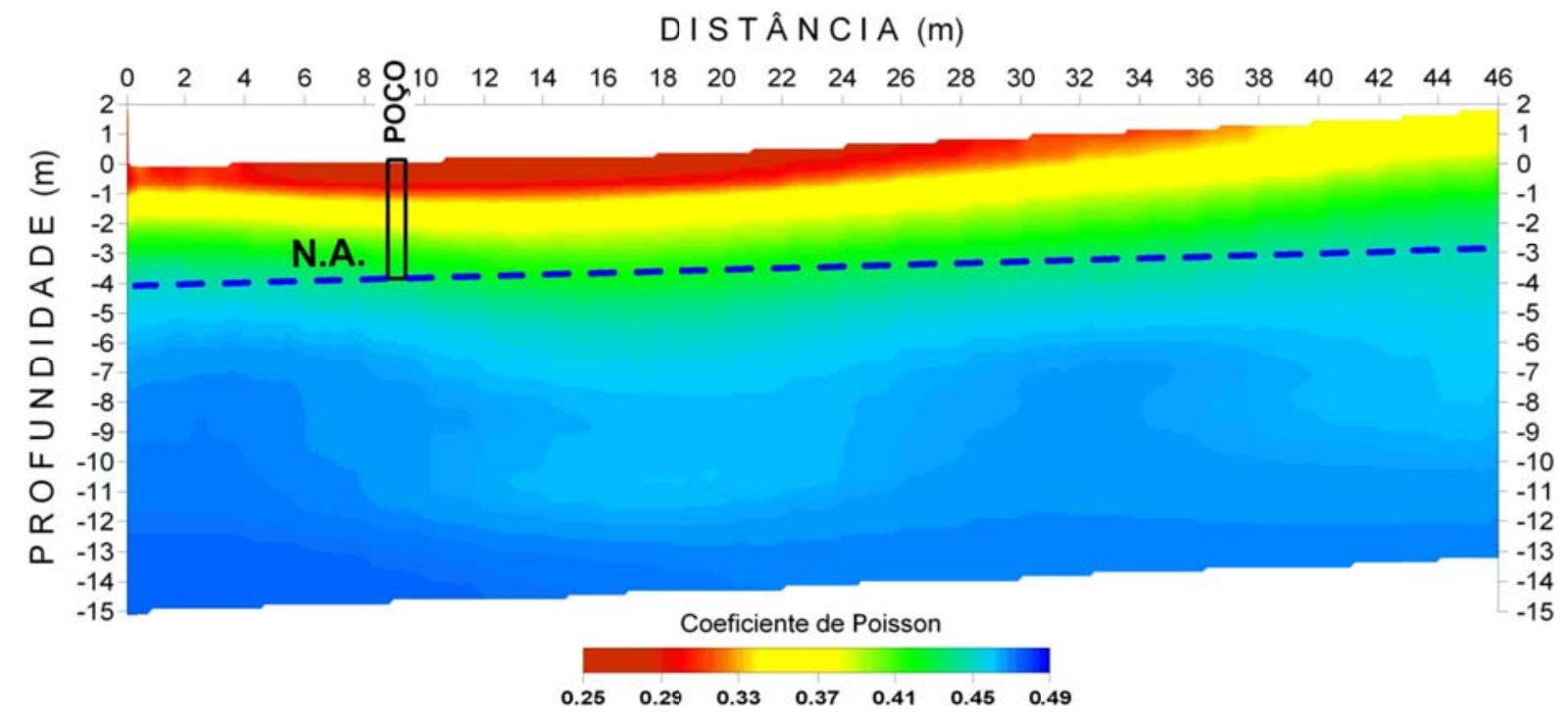

Figura 5 - Seção do coeficiente de Poisson determinada a partir dos modelos de $V_{P}$ (Figura 2) e de $V_{S}$ (Figura 3). 